\title{
The Uses of Indigenous Technical Knowledge in Development
}

\section{Michael Howes}

Academic concern with indigenous technical knowledge dates back at least as far as the first intensive fieldwork by anthropologists, ${ }^{1}$ but only in recent years has the possibility of using such knowledge as a basis for development activities been entertained. The change has arisen with the entry of members of other disciplines-notably geography and ecology-into this field, and may be attributed to a number of factors. Perhaps the most notable are the 'energy crisis', and the rapid growth in interest in systems not dependent upon non-renewable fossil fuels for their survival (Ariyartne 1976, Schumacher 1973), the incidence of largely man-made ecological disasters such as the recent drought in the Sahel, the accordant search for explanations and possible solutions (Wisner 1976, Swift 1975), and the phenomenon of the 'Green Revolution', which in spite of notable successes, has illustrated the problems inherent in strategies seeking to promote new technology 'from the top down'.2

This paper is prompted by these and similar concerns, and has two central related objectives. ${ }^{3}$ The first is to draw together a sample of the literature dealing with the scope, nature and propensity for change of the technical knowledge embedded in various third world social systems. The second is to explore ways in which such knowledge might be used in combination with established sciences and technology-to produce $R$ and $D$ systems more sensitive to the needs of the masses of people inhabiting the rural areas of the world's poorer nations. My intention is to identify the range of options which are, in principle, open to those seeking to attain such a goal, and to indicate broadly the circumstances under which they might prove feasible. It is not in any sense to prescribe what ought to be done. This can only properly be determined through active involvement in change programmes, and

\footnotetext{
1 See, for example, Radcliffe-Brown, 1964. This monograph, based on fieldwork carried out in the 1900s has an appendix dealing with technology, but as is typical of works from this period, little or no attempt is made to relate this to the functioning of the social institutions which the author takes as his central concern.

2 For a recent and comprehensive treatment of this issue, see Dasgupta, 1977

3 The paper should be read in conjunction with the annotated biography (infra); most of the work for which was carried out by Liz O'Keefe.
}

with regard to the nature of the existing technological base and the ongoing relations-both ideological and material-between indigenous populations and the representatives of established science.

Advocates of an extended role for indigenous knowledge have argued against the assumptions of a model which, in its simplest form, has two 'boxes'. In box A, an activity called 'research and development' goes on, the outcomes of which are new techniques or 'innovations'. These are then transmitted to box $B$, where production takes place, by means of a process known variously as 'dissemination', 'extension' and 'outreach'. Put slightly differently $A$ is represented as an entirely independent, and $\mathbf{B}$ as an entirely dependent variable; and if an 'improved' technique generated in A fails to take root in $B$, then this can only mean that something has gone wrong with the process of transmission, or that some change is required in $B$ itself.

This model serves as a fairly adequate device for representing what happens in a developed economy where there are strong links between $\mathbf{R}$ and $D$ and production, and messages frequently pass between the two. When, on the other hand, the receiver is a peasant farmer, or there is considerable variation in the circumstances under which different producers are operating-as tends to be the case in tropical agriculture - then the model, in its simplified form at least, breaks down. Where this happens, the reaction generally is not to question the validity of the model itself, but rather to modify it to ensure the 'feedback' of information from B to A. Binns, for example, in criticising earlier development models, implicitly attributes their failure to the inadequacy of information flowing to those in decisionmaking positions (1977: 1). It is fairly clear that the same kind of reasoning lies behind both the IRRI 'agro-economic constraints network' (Reynolds, n.d.: 3) and the CYMMIT monitoring programmes described by Gladwin (Gladwin, 1976: 881).

\footnotetext{
4 A number of writers have pointed out that tropical environments tend to be more heterogeneous than their temperate counterparts. See, for example, Barker 1977:47 and Brokensha $1977: 5$. This clearly has implications for the transferability of western-type centralised research operations.
} 
Such 'feedback mechanisms' are not to be disparaged, since they can be useful, ${ }^{5}$ but as Reynolds has pointed out, they suffer the critical limitation of remaining "within the overall philosophical position that knowledge is to be transmitted from research to farmers' (n.d.: 3). At worst, by preserving a rigid 'us and them' dichotomy where the farmer is confined to a passive role, the type of data communicated back is only what the scientists themselves have prejudged to be important. At best, scarce skilled manpower is tied up in activities which might equally efficiently or more beneficially be carried out by farmers themselves. To what extent then, is it possible or desirable to break down the existing and near absolute division of labour between scientists and producers? There will be areas where control has to be left in the hands of those with lengthy and specialised training, but need this apply across the board? The first step is to determine the scope and nature of the existing base of technical knowledge among particular social groups.

\section{The indigenous technical base: potential for an extended role}

Those who have examined indigenous technical knowledge in depth have inevitably been impressed. In the sphere of 'ethno-botanical' knowledge, for example, observers of a range of different societies have commented on the number of different species which individuals can identify, the degree of precision with which species are differentiated, and the high level of consistency found between different members of the same group. A ! Kõ bushman informant was able to identify by name 206 out of 211 varieties collected, and could draw finer distinctions between different types of plant than the professional taxonomist for whom she was working (Heinz and Maguire n.d.: 13). Conklin's research among the Hanunoo-a tribe in the Philippines practising swidden agriculture-revealed that an average adult could identify a staggering 1,600 different species, which was some 400 more than had previously been recorded in a systematic botanical survey (1957: 44), and Richards has similar observations to make regarding different groups of peasant farmers in Nigeria (1975: 109 110).

\footnotetext{
5 Gladwin (p. 881), for example, has pointed out how the use of such a mechanism by CIMMYT in Mexico led to the realisation that none of the new maize varieties being promoted were capable of out-performing those already in use, and the consequent decision to focus on means of improving the yields of existing varieties.
}

Hand in hand with this highly developed ability to identify plant life, goes a detailed knowledge of medicinal and other uses of plants and the conceptual wherewithal to deal in a sophisticated manner with relations between vegetation and the rest of the ecosystem. This again is clear in the case of Hanunoo, where Conklin found four different terms for describing the firmness of soil, nine colour categories to reflect its properties, 10 basic and 30 subtypes of rocks, five different topographical types, three different ways of categorising slopes, and six major and 10 minor types of vegetation grouping (1957: 36). Drawing on a similarly detailed framework, the ! Kõ are able quickly to locate individual plants of particular species through their intimate understanding of the principles governing the co-location of different plants according to soil conditions (Heinz and Maguire, n.d.: 14). These cases suggest that the perceptions of indigenous observers are not only superior to those of the scientist as far as the identification of individual species is concerned, but that this superiority also extends to the empirical understanding of localised eco-systems as a whole.

Indigenous knowledge is also often likely to hold a comparative advantage in awareness of changes in eco-systems. In the absence of reliable records, for example, older informants may be used to report the nature of relatively long-term ecological changes, and work carried out on a particular type of grasshopper which attacks cassava and other crops in Nigeria, has demonstrated that indigenous observers can record with precision the nature and extent of problems arising within shorter time scales (Barker infra et al. 1977).

To summarise, indigenous observers possess assets in the form of empirical knowledge of the individual elements of their eco-systems, of the relations through which these elements are conjoined, and of the way in which these relations change through short and more extensive periods of time. ${ }^{6}$ Naturally the size and the utility of these assets will vary both within and between social groups. The existence of these assets points to three areas where indigenous participation could prove feasible, and where the scope of established science could thereby be substantially increased.

\footnotetext{
6 The empirical nature of the knowledge should be emphasised. The indigenous observer clearly does not understand an ecosystem as a system in the way in which a scientist does, but will almost certainly have perceived fragments of it in operation which will have eluded the scientist, and which the latter could use as a means of arriving at an enhanced understanding of the underlying relationships at work.
} 
In the first place, knowledge of soils, rocks, vegetation, and so forth could provide a short cut to determining the effective resource base in an area or region. Gibbon's work in the Western Sudan suggests that by using local informants it may be possible to carry out a perfectly satisfactory soil survey and mapping exercise in a few days when a more conventional approach could take several months. ${ }^{7}$ The use of local informants in this way could serve not only to increase greatly the range of activities possible for scarce scientific manpower, but could help to build up the self-esteem of the indigenous participants-so creating a human resource which can be tapped in the pursuit of other development goals at a later stage. It is, however, important to note that such results are only likely where the scientist involved holds a positive attitude towards indigenous knowledge. Faniran and Areola, for example, ostensibly set out to understand local conceptions of resources and resource utilisation among communities in the Western state of Nigeria, but in practice appeared to be doing little more than testing local knowledge against their own preconceptions of how the environment could best be exploited. Thus the potential contribution of the indigenous population is played down because, among other things, they fail to perceive the possibility of developing the region for tourism! (Faniran and Areola 1976: 47). For all this, using local knowledge as a short cut to compiling an inventory of resources seems a relatively uncontroversial idea, and one likely to prove applicable across a wide range of situations.

The second major function for indigenous knowledge advanced in the literature is as a basis for an environmental monitoring and early warning system. The example of the cassava-eating grasshopper cited above was, in fact, reconstructed from informants' accounts by outsiders after the problem had become serious, but it is not difficult to envisage ways in which the indigenous knowledge and recall on which the study was based could have been tapped in advance. Similarly, indigenous observers could be used to bring problems induced by abnormal climatic conditions, or cases of environmental degradation, to the attention of scientists quickly and efficiently, so improving the chances of remedial action whilst restricting the demand for scarce scientific manpower to those areas where they would be deployed most effectively.

\footnotetext{
7 Personal communications to Robert Chambers.
}

The third possibility could involve indigenous observers acting as the 'eyes and ears' of science. This could entail, for example, monitoring the performance of different plant varieties or cropping patterns under a range of local conditions. To some extent this already happens, but with emphasis on the 'feedback' of information which scientists themselves consider important. An alternative approach would be more open-ended, allowing producers greater scope to structure their own observations according to what seemed most important to them. This would almost certainly improve the quality of the information flowing back to decision-makers, countering the present bias in such operations towards quantification.

But should indigenous populations simply be confined to acting as 'eyes and ears', or does the depth and breath of local knowledge not warrant some more fundamental role in the development process? A sizeable body of literature suggests that it does. It is necessary here to recognise the importance of the holistic view of a localised eco-system, which can only realistically be achieved through the active collaboration of an observer within its boundaries (Mikesell 1970: 42). In the case of the grasshopper, an external observer-perhaps charged with the specific task of pest eradication-could well have overlooked the significant fact that the insects were eaten and could contribute substantially to the diet of children; something which the people affected would almost certainly wish to take into account in determining the priority to be attached to the implementation of remedial action (Barker, infra). The importance of the inter-relation of apparently diverse factors at the grass roots level, and the potential danger of the selectivity of the external scientist or agent, has also been noted by other writers. Longacre cites the case of a cropping strategy introduced to raise incomes but which at the same time lowered nutritional intake on the part of the producer population-a dimension which the Ministries promoting the system had failed to consider (Longacre, n.d.: 25).

Localised indigenous knowledge may also provide the basis for the preliminary formulation of hypotheses which may then be referred 'upwards' for refinement and specific testing. Observations of the habitat of a pest, or its preference for certain crops as opposed to others, or of its relation to specific climatic conditions, might all provide at least useful short cuts for scientists in their search for effective remedial action.

This completes the discussion of those policy options for the utilisation of indigenous know- 
ledge which imply broad complementarity between it and organised science, within a framework where the latter retains its traditionally active and dominant stance. In implementing these, the first, and arguably the most important variable is the political will of those in positions to set those possibilities in motion. Little is likely to be achieved without the precondition of scientific respect for indigenous knowledge. The realisation that the shortage of skilled manpower makes some form of participatory approach a necessity provides as good a starting point as any for exploring the kinds of option which have been spelt out, but success is unlikely to follow if those implementing such programmes do so with the feeling that they are no more than 'second best'. ${ }^{8}$

Beyond this, variations within and between societies will also determine broadly what might and might not be achieved, and the types of procedure which should be adopted. In the case of societies operating under similar environmental conditions, the critical variable will be the level of technology attained. This emerges very clearly from Chapman's work on the 'ethno-scientific' knowledge of tribal and other groups in Bihar. The tribal peoples, operating at a relatively simple level of technology, were found to have a very rich vocabulary for dealing with the local fiora and fauna, whilst the groups where production was organised in more complex peasant farming systems, had a predictably far wider vocabulary for dealing with agricultural operations (Chapman, 1977: 19). It would be dangerous to attempt to read too much into what are undoubtedly somewhat crude numerical indicators, but it would seem likely that the tribal groups would prove rather stronger in an exercise designed to compile an inventory of locally available resources; and that peasant groups, with higher levels of literacy, might prove the more valuable partners in exercises where the fairly accurate recording of data over an extended period of time was required. ${ }^{9}$

\footnotetext{
\& Referring to the Gambia, for example, Development Alternatives Incorporated (1975, Vol. II: B33) has this to say: "In spite of the priority given (to agriculture), the Ministry of Agriculture and Natural Resources suffers from a lack of support and is understaffed. To make up for these deficiencies, the government emphasises farmer involventent in decision making and programme development'.

The clear inference is that participation is sought only because preferable options are foreclosed: hardly an ideal foundation upon which to build success.

9 The possibility of devising methods of recording which could he operated by the non-literate should not, however, be ruled out here.
}

An important and related point is that certain types of knowledge may be destroyed in the course of 'development', and may only be retrievable from informants in societies with relatively simple levels of technology. For example, Kate Young has pointed out that women in Latin America have traditionally retained a detailed knowledge of herbs which may be used to tide families over periods of food shortage, but that for a variety of reasons related to 'modernisation' and the incursion of cash cropping systems, this is not being passed on to their daughters. There is a greater dependence on good harvests than was previously the case, and correspondingly greater hardship among the poorer people in particular when harvests fail. Apart from the fact that women are less able and/or inclined to pass on such information, there is, of course, also the problem that the habitat itself changes, and that certain plant varieties disappear as cash cropping systems are introduced. ${ }^{10}$

With regard to the variability of knowledge within societies, a distinction should again be drawn between those operating at a simple level of technology-where it seems that technical knowledge is almost equally accessible to all adults (Conklin, 1957: 149, Heinz and Maguire, n.d.: 3)-and those where more sophisticated techniques have led to increasingly complex divisions of labour, increasing internal differentiation of social structure as a whole, and differential access to knowledge. Any type of collaborative venture with science could be undertaken with societies in the first group in the reasonable assurance that the outcome would be equitable; but the same could not be said of a society where substantial class differentiation had already taken place. Here a conflict might well arise over the class which scientists chose to interact with. There might be a trade-off between short-term 'results' (possibly obtained through working with the most articulate and powerful), and longerterm and more fundamental considerations of equity.

Whatever the level of technology, there will always also be the possibility of specialisation of knowledge drawn along sexual lines. In addition to the Latin American case cited above, Chapman found that women he studied in one of the groups were far better than men at distinguishing different varieties of rice (1977: 33), implying that they might well be more reliable partners than men in certain types of joint venture with

10 Kate Young, personal communication. 
science. It should however be emphasised that no simple or general statements can be made about the types of difference which are likely to arise, even among societies at a similar level of technology. Thus Heinz and Maguire expected to find a more detailed knowledge of vegetation among ! Kõ women because the task of collecting plants fell to them; but in fact it transpired that men were equally knowledgeable-partly because of the greater area they covered in the course of their own activities (Heinz and Maguire, n.d.: $3)$.

A generalisation more likely to hold across a range of societies is that the old possess greater stores of detailed knowledge, and prove more valuable informants where it is imprtant to establish the nature of changes occurring over extended periods of time (Heinz and Maguire, n.d.: 18). A final variable to be taken into account in determining the feasibility of different forms of collaborative interaction between science and indigenous knowledge, is the degree of linguistic uniformity with which the latter is expressed. In the case of the ! Kõ cited earlier, there was a very high degree of terminological agreement between different members of the society, even where handling intraspecies distinctions too fine to be dealt with by a trained taxonomist; and this would clearly facilitate communication with scientists external to the system. Conversely, where such uniformity does not exist, as in the case reported by Barker, where the same species of grasshopper would be given a different name from one village and even from one household to another, then the task of establishing collaborative relations necessarily becomes more complex (Barker et al, 1977 36).

How such problems can be overcome, or indeed whether it is worth looking for solutions, is something which can only be determined by the direct exposure of scientists to specific situations. The balance of the evidence presented so far however does suggest a general potential sufficient to justify the widespread exploration of the novel but relatively uncontroversial alternatives which have been outlined.

\section{Alternative modes of interaction with organised science}

The possibilities discussed so far all derive from the demonstration that the indigenous observer is a sound empiricist, who can safely be relied upon to extend the range of data channelled to the scientific decision maker. They presuppose systems, in other words, which do not depart radically from existing practice, in so far as the real power of decision making remains in the hands of organised science. Such systems-where the ends towards which developmental activities are directed and, in large measure, the means by which they are to be attained, are not determined by the people most directly affected-may well constitute the usual optimum solution from the point of view of the people themselves. But this need not always be so. In some cases indigenous practice, or the indigenous conceptualising of a problem or phenomenon, may prove comparable or superior to that of established science (Chapman 1977). On other occasions, indigenous and scientific perspectives may diverge, but both embody important insights (Horton 1967), thus suggesting the desirability of synthesis. Either way, there would appear to be a case for establishing relations which transcend the conventional science/indigenous, active/ passive dichotomy, and allow greater indigenous participation in the determination of both developmental goals and means. Three illustrations may now be explored-two of which are comparatively minor and one more substantialwhich hold precisely this implication.

The first of the minor instances is the Bihari system of time reckoning, which divides the calendar into periods of a modal length of 13 days, and provides a far more satisfactory means of conceptualising the agricultural cycle and its location within the context of seasonal change, than does the conventional western calendar (Chapman 1977: 8-9).

The second conveys a more fundamental divergence between scientific and indigenous perspectives. The traditional African approach to healing locates the origins of a disease within the social context of the afflicted individual rather than attributing it to, and dealing with it as, infection by germs. According to Horton, this provides an illustration of an approach which appears to work, but not to be readily assimilable by western medical science (1967: 56). In principle there would seem to be no good reason why both types of explanation, together with the diagnostic and healing practices with which they are associated, should not be simultaneously admissable as a means of dealing with the same phenomenon. In practice, however, entrenched positions, and an unwillingness to accept something which seems from the western point of view to be inextricably bound up with superstition and irrationality, lead to the African perspective being rejected. 
In this case, where the germ theory is allowed to prevail over its psychosomatic 'opponent', the damage incurred is perhaps not too great, since, if one is forced to choose, probably the former has greater validity. In other instances however, the implications of failure to accommodate a valid indigenous perspective may be more serious.

Perhaps the most dramatic illustration of this arises from the juxtaposition of science-based monocultural cropping regimes with the multicropping systems more conventionally favoured by the dryland tropical cultivator. The former derives from a world view where society is conceived as an entity apart from nature, able to manipulate its environment in the pursuit of its own ends (Langley 1975: 91). At a more concrete level, such beliefs provide the basis for the development of high-yielding varieties, seldom noted for their hardiness, but able to survive and flourish in artificially created and highly simplified eco-systems, supported by nonbiological inputs (Rappaport, 1971: 133).

Most observers concede that this strategy has led to dramatic increases in yield, although the superiority of mono-cultural practices from even this point of view is now contested in certain quarters. Norman, for example, summarising the results of research in a number of different African countries arrives at the conclusion that 'although the yield of (some) crops in mixtures declined compared with their yields as sole crops, this decrease was off-set by the yields of other crops so that inter-cropping gave a higher cash return per acre than pure stands' (1968: 155). Further support for this point of view comes from such writers as Rappaport (1967), on New Guinea swiddening, and Igbozurike (1971), on mixed cropping systems in Nigeria; both argue that the co-existence of plant species with different stem lengths serves to optimise the intensity with which a given unit of land may be exploited. Igbozurike has also suggested that the simultaneous cultivation of different crops serves to smooth out peaks of labour demand, and therefore to increase per capita productivity (1971: 528); and Norman makes a similar point with regard to the number of harvests which may be extracted from a piece of land in a fixed period of time (1975: 4).

The major argument against monoculture and in favour of mixed cropping systems, however, has been in terms of relative ecological stability and long-term productivity of land. At its simplest, the case against monoculture on these grounds boils down to two basic points. First, it is antithetical to the 'natural order' (Igbozurike, 1971: 521), emphasising simplicity rather than complexity and homogenity rather than diversity, and must therefore constantly be protected from invasion by other plants better adapted to the environment. For the same reason, monocultural systems are also highly vulnerable to invasion by pests. Secondly, it relies for its survival upon externally procured and non-renewable energy sources which must eventually run out. In Gandhian terminology, monoculture draws on the 'reservoir' as well as on the 'current' economy.

Indigenous mixed systems of cultivation, whilst arguably less productive in the short run, are by contrast stable, self-provisioning and effectively self-regulating. They are the concrete expression of world views which do not regard human society as something apart from 'environment', but emphasise the unity and symbiosis of man and nature. The scientific concept of eco-system, at least in its contemporary sense where 'nature and culture are seen not as opposing forces or separate entities, but rather as interlocking components' (Mikesell, 1970: 42), represents a rather belated recognition of the general validity of indigenous practice, which only a few years ago would have been characterised as irrational and unjustifiably conservative.

Given that indigenous knowledge can contribute to a broader scientific enterprise in ways more fundamental than those made possible by virtue of its simple 'empirical' range, what further scope exists for increasing indigenous participation in the processes of teclinical change? In the light of his own observations on the superiority of mixed cropping systems, Richards has concluded that 'an idea borrowed from the people, developed by the agronomist and returned to the people, is much more likely to be adopted than something alien to the culture' $(1975: 110)$. The model implied, where an initial process of scientists' familiarisation with indigenous knowledge enables them to internalise and operate in terms of the 'ends' towards which indigenous efforts are directed, would often represent an advance on the present predominantly unidirectional determination of research activity, but would still not be without its difficulties. It would require either a highly developed sense of empathy in those from individual disciplines, or the mounting of a multi-disciplinary approach with the problems of co-ordination this inevitably entails. Secondly, it would share with unidirectional approaches the 
disadvantage of restricting the users of a new technique to an almost entirely passive role. Given the variability of tropical environments, and finite scientific manpower, this could mean only one of two things. Either new technology would be rather inflexible and ineffective in a wide range of environmental conditions encountered, or suitable adaptation to local circumstances could be attained at the expense of not being able to replicate the advances achieved across substantial geographical areas.

In principle, the easiest way out of this conundrum would be greater indigenous participation in the generation and exploitation of new techniques, but how feasible would this prove in practice? An interesting article by Johnson suggests that a strong basis for developing such initiatives already exists, but has gone largely unrecognised as a result of the general tendency to regard indigenous agricultural systems as incapable of generating within themselves the momentum for change. Johnson's basic point is that, for the enormous diversity of practices within any agricultural system, by no means all can be accounted for in terms of regularised institutional responses to differences either in physical conditions or in social and economic circumstances. There will always be a residual category reflecting the combination of uncertainty and complex circumstances which becomes 'the non-formal experimental basis of individual skills' (1972: 153); although, of course, over a period of time, the outcome of the individual experiment may itself become a part of the social body of technology. Further evidence of the likely universality of what might best be described as the 'experimental mentality'-at least where relatively little risk is entailed-comes from Conklin's account of the Hanunoo, where in what is apparently the most stable of agricultural systems, great interest is shown in unfamiliar plant varieties, which are tested on small plots near to people's homes (1957: 110).

Whilst there are general indications such as these that dynamic processes of experimentation do operate in supposedly 'traditional' settings, the available literature gives little or no insight into specific cases of agronomic/biological innovation occurring at the grass-roots level. In the sphere of engineering, however, where the process of innovation is perhaps more readily perceptible to the external observer, a limited number of examples are available, and provide more concrete evidence.
Perhaps the best known of these is the bamboo tubewell, which first appeared in Bihar in the late 1960 s and subsequently spread rapidly. Faced with the problems that water supply from canals was unreliable, and that the tubewell being promoted by the government used very expensive iron piping, farmers themselves began to explore other possibilities. The outcome, after a period of experimentation, was a far cheaper alternative comprising locally available bamboo pipes, nailed together with iron rings, and covered with bamboo coir (Dommen, 1975: 484-5). A similar example of an externally introduced and initially unsuccessful innovation being adapted by potential users is reported from Vietnam (Sansom, 1969), and emphasises once again the very substantial pool of innovative capabilities which exists beyond the formal and established system of science and technology.

The case of the bamboo tubewell illustrates other important points about how the process of innovation works at the grass roots level. The first, emphasised by Clay, and in contrast to the view presented by Dommen, is that the innovation could not properly be attributed to one 'inventor', but was the culmination of a process of smaller breakthroughs achieved by several individuals (Clay, E. J., personal communication). This is important because it shows that the capacity to experiment is relatively widespread, and not-as many observers apparently feel the need to suggest-the prerogative of a small elite who stand in relation to the rural masses much as does the scientist in the conventional models discussed earlier.

The second point to emerge from this case is that the innovation was not simply demandinduced, but had to be accounted for in terms of a situation where the social heritage of knowledge and techniques was the real source of invention. Clearly the need for water played its part, but this would have gone unanswered had it not also been for the available supply of knowledge of the properties and potential uses of bamboo and coir. This again suggests that indigenous knowledge should not simply be regarded as something drawn upon to contribute in passive fashion to change, but may be more usefully represented, rather like capital in the field of economics, as containing within itself the potential for growth and transformation.

Whilst there is a sizeable literature on the empirical scope of indigenous technical knowledge, and at least a limited amount of material 
on the more abstract principles governing the organisation of this knowledge, scarcely anything can be found which treats indigenous knowledge as a dynamic entity, or deals with the mechanisms whereby it is accumulated. A first step towards such understanding might entail the study of a related and similarly neglected set of questions-namely the way in which elements of the established store of technology are transmitted between individuals and through succeeding generations. At this stage, however, it is more pertinent to inquire into the reasons why even those who appear favourably disposed towards an extended role for indigenous knowledge, do not advocate or even consider ways in which the existing propensity to experiment might provide the basis for direct participation in the process of creating new knowledge on the part of the indigenous populations.

\section{The limitations of the 'utilitarian' perspective}

Why then has the potential of producers to participate themselves in the processes of experimentation and innovation been largely overlooked? As far as those who are on the side of indigenous knowledge are concerned, the origins of the problem may be located in the notion that such knowledge is primarily 'utilitarian'. ${ }^{11}$ This notion appears to be a reaction against the earlier view that indigenous knowledge was inherently mystical and irrational (Horton, 1967) and is widely accepted in the literature so far reviewed. Brokensha and Riley, for example, state quite categorically that: "utilitarian value is paramount within indigenous classificatory systems' 1977: 7), a sentiment echoed by Heinz and Maguire when they refer to taxonomic "concepts born out of the almost exclusively utilitarian needs of the primitive society' (n.d.: 15).

In spite of the apparently bold conviction of such statements, an element of uncertainty and qualification tends to arise when the precise nature of 'utilitarian value' is questioned. Heinz and Maguire, for example, suggest that the knowledge of the !Kõ bushmen extends substantially beyond those plants which are of direct economic value, but argue that such knowledge is still utilitarian because it may be used to indicate where directly useful plants may be found (n.d.: 16). This is somewhat less than convincing, and makes it difficult to conceive of identifying any plant which could not by some criterion or other be

11 This is the term used by proponents of the view themselves. To avoid possible confusion it should be pointed out that it is a synonym for 'of direct practical use'. deemed 'useful'; and certainly no evidence is produced of the existence of species which people neither use nor are able to identify. In other words, the utilitarian argument slips very easily into tautology. It must also be said that remarkably little hard evidence is summoned to support this point of view.

Ultimately, however, the value of the utilitarian case cannot be established on this basis, but must be judged in terms of its implications for the way in which indigenous knowledge is regarded. Labelling indigenous knowledge as utilitarian implicity denies it an abstract or intellectual dimension, and effectively excludes from consideration its potential for independent development and growth. ${ }^{12}$ In common with all theories which seek to represent social phenomena as entities which arise in response to needs, the utilitarian view cannot adequately account for change, other than in terms of a reaction to pressure from outside the social system in question. ${ }^{13}$

In trying to deny the validity of the distinction drawn between scientific and indigenous knowledge on the grounds of the former being rational and the latter irrational, the utilitarian view therefore only succeeds in replacing it with another unacceptable dichotomy. A more useful formulation, according better with earlier observations on the propensity for indigenous experimentation, is presented in Levi Strauss' proposition that:

$\therefore$. the thirst for objective knowledge is one of the most neglected aspects of the thought of the people we call "primitive". Even if it is rarely directed towards facts of the same level as those with which modern science is concerned it implies comparable intellectual application and methods of observation. In both cases the universe is an object of thought, at least as much as it is a means of satisfying needs' (quoted in Reynold n.d.: 3).

This does not deny the existence of differences. As Horton has pointed out, science has at its disposal means to 'bombard' reality through controlled experimentation which are denied to the indigenous observer, and other distinctions may be drawn with greater and lesser degrees of

12 On occasions, this point is made quite explicitly. Barker et al., for example, argue that: "the farmers" approach to knowledge is utilitarian, and disinterested observation for observation's sake is a luxury not often affordable" (1977: 21).

13 The utilitarian position is subject, in other words, to all of the objections levelled at functional theory in anthropology. For a detailed critique of this aspect of functionalism, see Cohen (1968), especially p. 41. 
validity (Horton, 1967: 172-3). By identifying structural similarities in the way these different bodies of knowledge operate, the perspective does, however, provide an ideological incentive for the exploitation of new forms of interaction between scientists and producers, in areas which would have previously been considered the exclusive prerogative of organised science. A necessary first step here would involve a systematic search for the abstract principles and categories which govern the ordering of the bodies of empirical knowledge discussed earlier in the paper. The literature reviewed has remarkably little to offer on this score, although the odd passing reference suggests that fieldwork inquiries conducted with this problem in mind could prove highly revealing (e.g. Conklin, 1957: 43-44).

As in the other areas where there appears to be scope for a more active role for indigenous technical knowledge, it must again be emphasised that the extent of desirable departure from the existing divisions of labour will vary with the type of problem. A high degree of devolution may well be appropriate in fields such as agronomy and plant breeding, with producers joining in adaptive breeding experiments and helping to determine the characteristics to be bred and tested for. In other fields, where environmental specificity is not so important, a more conventional centralised approach may make better sense. This issue cannot be taken much further here but should be placed on the agenda for future consideration.

Two cases can be mentioned where a high degree of indigenous participation was secured in the problem identification and solution seeking phases of innovation. The first concerns the construction of water storage facilities in a Dogon village, where an external team acted as a catalyst and provided limited technical inputs when asked to do so, but where villagers drew on their own technology and made most of the important decisions for themselves (Guggenheim and Fanale, 1976). The second derives from an application of Paulo Freire's methods of 'education through problem posing' to the question of nutrition in four Brazilian villages. Here, small teams of specialists first of all explained the energy and growth needs of children to villagers, and then, in much the same way as in the Dogon case, acted as catalysts in discussions designed to locate solutions which lay within the grasp of the people themselves (Longacre, n.d.). The final outcome is not altogether clearpeople taking interesting initiatives often fail to record the important lessons their experience might hold for others-but apparently villagers were led to a heightened awareness of the nutritional value of available foods, and set up their own apparatus for monitoring the children's health.

Both these cases provide glimpses-however elusive-of what might be attained on a wider scale; but a number of sizeable question marks remain. First, neither writer gives any indication of the skilled manpower required by these exercises, which makes it impossible to form any clear impression of their potential replicability. (In the absence of evidence to the contrary, the suspicion must be that the time input required to achieve positive results was high.) Second, the innovations in question appear quite simple. This is not to underestimate their potential importance, but doubt must remain over the extent of the technical sphere within which such approaches might prove feasible. Finally, it has to be borne in mind that both cases appear to involve relatively informally constituted groups of external scientists or technologists. This again is all right in itself, but could the approach operate within a more formal institutional framework, as it almost inevitably would have to if it were to be applied on a substantial scale?

These are only the first of a number of considerations which must be taken into account in determining the likely feasibility of different options under different circumstances. One other important initial consideration will be the degree of flexibility adopted by scientists themselves. The potential for increased indigenous participation in any of the processes discussed will depend on the extent to which they can display, in Mao's words: 'a determination to direct one's eye downwards', and can shed 'the ugly mantle of pretentiousness and become a willing pupil' (Mao, 1971: 196). This applies equally to extension agents, and other lower-level government personnel who deal directly with farmers and peasants. Indeed. the problems of securing the co-operation of this group may be even greater, since they are often from humble backgrounds themselves, and may have a vested interest in denigrating indigenous knowledge and exaggerating the significance of the modern scientific practices with which they are associated, as a means of enhancing their own status.

\section{Village ecology and political economy}

Science, however, does not exist in an ideological vacuum, and such a transformation will be 
difficult to attain given the prevalence of the 'unidirectional' models discussed above, and the tendency to denigrate indigenous knowledge (O'Keefe and Wisner 1975: 35). Neither is the problem simply one of ideology, since such attitudes are closely related to more fundamental patterns of economic inequality (Benneh and Semiti, 1976: 20), which have in turn been responsible for the destruction of indigenous knowledge, and the reduction in the number of options open at the grass roots level (O'Keefe, 1976: 35, Brokensha and Riley, 1977: 21-2). But perhaps the most serious problem is that indigenous populations themselves have now come to accept that there are different types of knowledge, and that their own is inferior. ${ }^{14}$ Chapman, for instance, cites the example of a farmer who adopted chemical fertiliser as a 'modern practice', and at the same time abandoned the 'traditional practice' of green manuring, although the latter was more appropriate to his circumstances (1977: 30); and a similar case is described by Barker (1977: 19).

The perception of such forces has led certain supporters of indigenous knowledge to suppose that relatively little can be achieved in the sphere of 'technical sharing' until more fundamental and underlying structures of relations have been transformed (Soysa, 1977). Others such as O'Keefe and Wisner (1976) and Herrera (n.d.) speak rather more optimistically of the possibility of a synthesis between established science and the more progressive elements of traditional society, but at least imply that some form of socialist transformation will be necessary to bring this about; essentially the same conclusion is reached by Barker (1977: 51). Much, of course, will depend upon what type of socialist relations one has in mind here; it would be difficult, for example, to conceive of anything more antithetical to the spirit of what these writers intend than a soviet style 'command economy'. One would expect the kinds of approach discussed to flourish more readily in a society which minimised status and class distinctions as a general principle, but at the same time, as Hunter has implied (Hunter, 1974: 72-3), there must also be provision for individual initiative; and the balance between these two considerations will be difficult to strike.

Even if one shares the view that progress on a wide front can only be attained here after structural change has taken place, this does not

14. For a concise account of how such relations are created and preclude the possibility of more limited advance where such changes are unlikely. Richards, for example, argues a fairly convincing case for the introduction of progressively more controversial ideas on an incremental basis in Nigeria (Richards, 1975: 114). Ultimately, as with the question of the degree of devolution of decisionmaking which might be appropriate in different areas, the problem of determining the economic and political contexts within which scientific and indigenous knowledge may be brought into fruitful interaction, must be assigned to the agenda for future consideration.

Such questions can best be answered through the active involvement of natural and social scientists in experimental programmes; and a number of recent initiatives in this sphere suggest that substantial advances in our understanding of the problems and possibilities involved may be anticipated in the near future (Ariyaratne 1976, Barker et al. 1977, Herrera n.d., Reynolds n.d.). These and more purely academic enterprises have very real potential not only for discovering answers in a detached and passive manner, but also for actively helping to determine the types of answers which might prove possible. Even where active involvement is not possible, this can be achieved by criticising ideologies which draw false distinctions between scientific and indigenous knowledge, thus simultaneously undermining the position of those who continue to advocate elitist models, and helping to build the confidence of people in their own particular knowledge and experience.

This paper has outlined three ways in which such a goal might be attained. The first would be to build upon the foundation provided by writers such as Conklin and Rappaport by demonstrating the empirical depth and breadth of the technical knowledge at the disposal of different social systems. The second, somewhat less well developed at present, might take as its point of departure contributions such as those of Levi Strauss and Horton, in seeking to represent more clearly the nature of the underlying principles by which such knowledge is organised. The third, following on from Johnson, would be to investigate in far greater depth the ways in which knowledge is transmitted and accumulated. The combined development of these three perspectives, particularly if pursued within a broader framework encompassing considerations of political economy (O'Keefe and Wisner, 1976: 119), could go a long way towards changing currently entrenched positions on the proper conduct of research and development. In so doing, it could lay the 
foundation for a system where producers-be they bushmen, shifting cultivators, peasants or farmers-could more readily bring their expertise to bear in the identification and ranking of problems, and the generation and implementation of solutions.

\section{References}

Ariyartne, A. T., 'The Sarvodaya Shramadana Movement: Mobilising Human Resources for Development', Peace Corps Program and Journal, vol VI, no 3, 1976

Barker, D., J. Oguntoyinbo and P. Richards, The Utility of the Nigerian Peasant Farmer's Knowledge in the Monitoring of Agricultural Resources: A General Report. Monitoring and Assessment Research Centre of the Scientific Committee on Problems of the Environment, International Council of Scientific Unions. MARC Report No 4, Chelsea College, University of London, 1977

Belshaw, D. G. R. and M. Hall, 'The Analysis and Use of Agricultural-Experimental Data in Tropical Africa', East African Journal of Rural Development, vol 5, nos 1-2, 1972

Benneh, G. and G. A. Semiti, 'Nutrition and the Human Environment', African Environment, Occasional Paper No 76-8, July, 1976

Binns, J. A. 'Integrated Agricultural Development: A Case-study from Sierra Leone', Oxford Polytechnic Discussion Papers in Geography, July 1977

Brokensha, D., and B. Riley, 'Vegetation Changes in Mbere Division, Embu', Institute for Development Studies, University of Nairobi, Working Paper No 319, 1977

Chapman, G. P., 'The Folklore of the Perceived Environment in Bihar', Dept. of Geography, University of Cambridge, 1977

Cohen, P. S., Modern Social Theory, Heinemann, London, 1968

Conklin, H. C., Hanunoo Agriculture. A Report on an Integral System of Shifting Cultivation in the Philippines, FAO Forestry Development Paper No 12, Rome 1957

Dasgupta, B., Agrarian Change and the New Technology in India, UNRISD, Geneva, 1977
Development Alternatives Inc., Strategies for Small Farmer Development: An Empirical Study of Rural Development Projects, Report to US/AID in three volumes: Final Report, Case Studies and Executive Summary, DAI, Washington DC, May 1975

Dommen, A. J., 'The Bamboo Tube Well: A Note on an Example of Indigenous Technology', Economic Development and Cultural Change, vol 23, no 3, 1975

Faniran, A. and O. Areola, 'The Concept of Resources and Resource Utilisation Among Local Communities in Western State, Nigeria', African Environment, vol 2, no 3, 1976

Gladwin, G. H., 'A View of the Plan Pueblo: An Application of Hierarchical Decision Models', American Journal of Agricultural Economics, vol 58, no 5, December 1976

Guggenheim, H., and R. Fanale, 'Shared Technology: A Project for Water Storage and Irrigation in Dogon Villages', African Environment Occasional Paper, No 76-1, March 1976

Heinz, H. J., and B. Maguire, 'The Ethno-Biology of the ! Kõ Bushmen: Their Ethno-Botanical Knowledge and Plant Lore', Occasional Paper No. 1, published by The Botswana Society, Gaborone, undated

Herrera, A. O., Scientific and Traditional Technologies in Developing Countries, undated (Mimeo)

Horton, R., 'African Traditional Thought and Western Science', Africa, vol 37, nos 1 and 2, 1967

Hunter, G., 'Indigenous Development and the Developing World', ODI Review, no 2, 1974

Igbozurike, M. U., 'Ecological Balance in Tropical Agriculture', Geographical Review, vol 61 , no 4,1971

Johnson, A. W., 'Individuality and Experimentation in Traditional Agriculture', Human Ecology, vol 1, no 2, September 1972

Langley, P., 'The Ethnolinguistic Approach to the Rural Environment: Its Usefulness in Rural Planning in Africa', African Environment Special Report No. 1: Problems and Perspectives, International African Institute, London 1975 
Longacre, D. J., Nutrition and Development, Mennonite Central Committee, Development Monograph Series No 4, Akron, Pa., undated.

Mao Tse-Tung, Selected Readings from the Works of Mao Tse-Tung, Foreign Languages Press, Peking, 1971

Mikesell, M. W., 'Cultural Ecology', in National Council for Social Studies, Focus on Geography, P. Bacon (ed.), Washington, 1970

Norman, D. W., 'Why Practise Intercropping?', Samaru Agric. Newsletter, Ahmadu Bello University, Zaria, Nigeria, vol 10, 1968

-'Rationalizing Mixed Cropping Under Indigenous Conditions: The Example of Northern Nigeria', Samaru Research Bulletin, 232, Institute for Agricultural Research, 1975

O'Keefe, P. and B. Wisner, 'African DroughtThe State of the Game', African Environment Special Report No. 1: Problems and Perspectives, International African Institute, London, 1975

-'Development or Underdevelopment: A Kenyan Case Study', African Environment, vol 2, nos 1-2, London, 1976

Radcliffe-Brown, A. R., The Andaman Islanders, Free Press of Glencoe, New York, 1964

Rappaport, R. A., Pigs for the Ancestors: Ritual in the Ecology of a New Guinea People, Yale University Press, New Haven and London, 1967
'The Flow of Energy in an Agricultural Society', Scientific American, vol 225, no 3, 1971

Reynolds, N. E., Ethno-Agriculture: Background Paper, undated (Mimeo)

Richards, P., 'Alternative Strategies for the African Environment: "folk ecologies" as a basis for community-oriented agricultural development', African Environment Special Report No. 1: Problems and Perspectives, International African Institute, London, 1975

Sansom, R. L. 'The Motor Pump: A Case Study of Innovation and Development', Oxford Economic Papers, vol 21, no 1, March 1969

Schumacher, E. F., Small is Beautiful: A Study of Economics as if People Mattered, Blond and Briggs, London, 1973

Soysa, C. H., 'Sharing of Traditional Technology', International Development Research/ Focus, 1977/1

Swift, J. J., Draft Report of the UNESCO/IDEP Seminar for West African Decision-Makers on Integrated Environmental Management, 1975 (Mimeo)

Wisner, B., 'Man-Made Famine in Eastern Kenya: the interrelationship of drought and development', Institute of Development Studies, University of Sussex, Discussion Paper No 96, July 1976 